\title{
SEBASTIÁN DE HOROZCO (1510-1580) Y UN CUENTO ANTICLERICAL SUYO ${ }^{1}$
}

\author{
JACK WEINER \\ Northern Illinois University
}

Este estudio tiene dos propósitos. El primero es mostrar el carácter anticlerical del cuento \# 238, «Los niños y los locos dizen las verdades», del recién publicado libro de Horozco titulado El libro de los proverbios glosados (1570-1580) (I:302-303). De ahora en adelante LPG ${ }^{2}$. El segundo propósito de este estudio es colocar el susodicho cuento dentro de la corriente picaresca y mostrar los rasgos que comparte con el Lazarillo de Tormes.

De las obras de Horozco publicadas antes de 1994 todas eran en verso, prosa periodística o tipo ensayo. Pero, en contraste, LPG es una obra que contiene veintenas de cuentos cortos, es decir, narraciones dignas de llamarse ficción. Tanto es así que hoy en día me inclino a creer que en realidad se trata del perdido y llorado El libro de cuentos. Esta obra, por primera vez la citó Tomás Tamayo de Vargas en 1624 (LPG I:6).

En 1576 el párroco de la iglesia toledana de San Vicente, Luis Hurtado de Toledo (1510-1598), escribe: «En Sant Juan Baptista enfrente de su yglesia esta el hospital del Nuncio [de Nuestra Señora de la Visitación] para la yncurable y contagiosa enfermedad de los locos, el qual fundó don Francisco Ortiz [1480] nuncio apostolico y canonigo de la Sancta Yglesia de Toledo» ${ }^{3}$.

Parece que poco después de la muerte de Francisco Ortiz en 1502 el Cabildo Catedralicio, «por algunas causas se entrometieron en ello...». Y

\footnotetext{
${ }^{1}$ Agradezco mucho a Dolores Henry el haberme ayudado a preparar este manuscrito y al personal de la Sección de Préstamo Interbibliotecario de la Biblioteca de mi Universidad. También agradezco su ayuda a Samuel Armistead, Terrence Beer, Harriet Goldberg, Reginetta Haboucha, Isaac Jack Lévy, James I. Miller y David Stern.

2 Sebastián de Horozco, El libro de los proverbios glosados, Kassel, Edition Reichenberger, 1994, 2 vols.

${ }_{3}^{3}$ Luis Hurtado de Toledo, Relaciones Histórico-geográfico... Felipe II: Reino de Toledo (tercera parte), ed. Carmelo Viñas y Ramón Paz, Madrid, C.S.I.C., 1963, págs. 557.
} 
que ya hacia 1554 dicho hospital pasaba por alguna crisis económica por problemas con su dotación ${ }^{4}$.

El hospital aceptaba a los «locos furiosos» (Alcocer $i b i d$.). Eran los que se hospedaban allí más o menos treinta y tres locos, trece niños expósitos ${ }^{5}$ y unos trece viejos enfermos y pobres ${ }^{6}$. De vez en cuando entraban mujeres (Martz 220). El patronazgo quedaba en manos del Cabildo, que lo administraba y proveía de un rector residente que tenía la responsabilidad «de las cosas tocantes al dicho ospital, proveyendo a los enfermos que en el ay de la cura necessaria a su enfermedad»(Alcocer ibid.). Había además dos canónigos que visitaban el hospital algunas veces al año para ver si se administraba debidamente (Martz 163). Es decir, observaban si los «inocentes», como llamaban a los locos ${ }^{7}$, vivían bien y recibían buen trato.

La entrada al Hospital era por examen del Cabildo. Es decir que sin permiso y sin el apoyo de personas importantes nadie podía entrar (Luis Hurtado 557).

Toledo era una ciudad con veintiséis hospitales, es decir, una ciudad donde había bastantes lugares y cofradías que se dedicaban a la beneficencia pública. Y sin duda alguna tal fama atraía a muchos necesitados de todo tipo. Linda Martz, hablando en particular sobre la Casa del Nuncio, dice: «Given the small number of people housed in the hospital what seemed to be the large number of prospective applicants who came from all over the Iberian península, the recommendation of a cathedral canon probably did help in gaining admission to the hospital» (Martz 220). Y efectivamente, según nuestro cuento Montejano era forastero [isalmantino? ${ }^{8}$ en Toledo, como él mismo dice «... un quento que aconteçió en mi tierra...», pues, «mi tierra» indica un lugar fuera de Toledo y confirma Sancho de San Román que en la Casa del Nuncio vivían forasteros también ${ }^{9}$.

\footnotetext{
${ }^{4}$ Pedro de Alcocer, Historia descripción... Toledo, 1554, Toledo, I.P.I.E.T., 1973, cxx, cap. xxxviij.

5 Julio Porres Martín-Cleto, Historia de las Calles de Toledo, Toledo, Diputación Provincial, 1971, I, págs. 12-13.

${ }^{6}$ Linda Martz, Poverty and Welfare in Hapsburg Spain: The Example of Toledo, Cambridge, Cambridge University Press, 1983, pág. 225.

${ }^{7}$ Gregorio Marañón, El Greco y Toledo, quinta edición, Madrid, Espasa-Calpe, S.A., 1968, pág. 227.

${ }^{8}$ Grace de Jesús C. Álvarez, Topónimos en apellidos hispanos, Garden City, Hispanófila, 1968, pág. 520, \# 421.

9 Rafael Sancho de San Román, «El hospital del Nuncio de Toledo en la historia de la asistencia pública», Anales Toledanos, XVII, 1983 ( págs. 56-71), pág. 64. Aunque el número de pacientes variaba a lo largo de los siglos, Francisco Ortiz estableció, según parece, el número de treinta y tres «inocentes», por el número de años que vivió Jesucristo y trece por el número de expósitos para corresponder a Cristo y a los doce apóstoles (Sancho 59). De importancia primordial sobre la Casa del Nuncio y su fundador es Francisco de Borja San Román, «Autobiografia de Francisco Ortiz y Constituciones del Hospital del Nuncio, de Toledo», Boletín de la Real Academia de Bellas Artes y de Ciencias Históricas de Toledo, XLVI-XLIX, 1931, págs. 4-28, y en Ervdición Ibero-Vltramarina, II, n. ${ }^{\circ}$ 9, 1932, págs. 121-144, passim.
} 
Teniendo en cuenta que el número de pobres y de locos que había en España era grande, y en Toledo en particular, muchos querían entrar en la Casa del Nuncio donde se comía, se dormía y en general no se vivía mal (Sancho 60-62) y los que allí residían no querían volver al mundo exterior.

Una de las obligaciones de los canónigos visitadores del Cabildo toledano era la de echar a los ya curados o, al menos, a los que ellos creían curados: «In 1575 the hospital housed a beata who some canons thought should be removed on the grounds that she was sane...» (Martz 220). Por eso el «Inocente» Montejano del cuento de Horozco bien sabía lo que tenía que hacer para poder permanecer en la Casa del Nuncio, como narra Horozco «... se quedó allí y estuvo hasta que murió» (LPG I:303).

Efectivamente Horozco en su cuento dice que estos dos canónigos del Cabildo toledano iban a visitar la Casa del Nuncio para ver qué enfermos se quedaban y cuáles se tenían que marchar por estar ya curados. Y por la mucha experiencia que las autoridades tenían en su trato con la demencia, sabían que era muy probable que los que estaban dentro no quisiesen salir de la Casa del Nuncio.

Según el cuento de Horozco, un día los dos canónigos designados por el Cabildo para hacer su visita entraron en la Casa del Nuncio, «para tomar quentas». Estos dos canónigos, hay que explicar, «tenían regresadas ${ }^{10}$ las calongías el uno a un hijo del otro y el otro al del otro» (LPG I:302). Este dato que Horozco nos descubre plantea una serie de situaciones que conviene explicar inmediatamente.

En primer lugar Horozco describe a los canónigos como padres biológi$\cos$ y a lo mejor sacerdotes concubinarios ${ }^{11}$. Según Las siete partidas, la ley castigaba a los sacerdotes no célibes ${ }^{12}$. Pero, en realidad, los sacerdotes se amancebaban y mantenían concubinas durante toda la Edad Media. En el siglo XVI los esfuerzos eclesiásticos para prohibir el amancebamiento o concubinato no tuvieron mayor influencia (Lea 263).

Los enormes esfuerzos del cardenal y arzobispo de Toledo fray Francis-

\footnotetext{
10 «Regresar. Vale también resignar o ceder el Beneficio à favor de otro. En este sentido es verbo activo... Cort. de Vallad, Año de 1537. f. 27. Assimismo, porque de regresar los beneficios se siguen muchos daños en estos Reinos, y se tiene y há por herencia de Padre à hijo, como los bienes que son de su Patrimonio». Diccionario de Autoridades, Madrid, Editorial Gredos, 1969, vol. III, pág. 550.

${ }^{11}$ Por supuesto había hombres ya viudos que se ordenaban. Tal es el caso de Antonio de Covarrubias quien se había casado con su prima doña María de Tapia, prima de Santa Teresa. Ver Jack Weiner, «Padres e hijos: Sebastián de Horozco y los suyos», Toletum, XXV, 1990 (págs. 109164), pág. 111, nota 2 y mi estudio «Sobre el linaje de Sebastián de Horozco», La picaresca, origenes y estructura, ed. Manuel Criado de Val, Madrid, Fundación Universitaria Española, 1979, págs. 790-824, passim.

${ }^{12}$ Henry C. Lea, The History of Sacerdotal Celibacy in the Christian Church, New York, Russell A. Russell, 1957, pág. 258.
} 
co Jiménez de Cisneros para crear un clero célibe, también fracasaron ${ }^{13}$. El cardenal llegó a construir un edifico «para los canónigos que ellos jamás llegaron a habitar, [lo cual] es un testimmonio, para la posteridad, de este quijotismo reformador» ${ }^{14}$. De manera que era común el sacerdote amancebado impunemente ${ }^{15}$.

Sobre el amancebamiento del clero en la época y en la obra de Sebastián de Horozco conviene estudiar su Cancionero, en particular los números $1,9,53,54,135,312$ y $347^{16}$.

Además del amancebamiento y de hijos ilegítimos este cuento nos llama la atención sobre otro tipo de abuso: los nombramientos para las canongías catedralicias. Estas canongías, según el Concilio de Trento, debían obtenerse por normas preestablecidas y obedecidas universalmente ${ }^{17}$, en función de la edad, estudios y moral del aspirante (Canons 201-202).

Pero, en realidad, el nepotismo era universal en muchas, si no en todas, las catedrales e iglesias colegiatas en España. Según Juan Maldonado, clérigo de la catedral de Burgos, en su tratado El buen pastor (1529), "Los examinadores... tienen sobre sí la pesada responsabilidad de la admisión a las órdenes y de la colocación de las prebendas. Desgraciadamente, no siempre son hombres íntegros» (Bataillon 300). Pues personas de poder y de dinero obtenían los cargos (Bataillon 332).

Tales abusos existían, por ejemplo, en las catedrales de Ávila ${ }^{18}$, Sevi$1 l{ }^{19}$ y Cuenca ${ }^{20}$. Si en una catedral no se pasaban las prebendas de tíos a sobrinos, se pasaban de padres a hijos. Eran tan escandalosos y comunes estos negocios que otro loco, el sevillano José Amaro Sánchez (c. 16501713) en su sermón XV111, "A una oposición de canongía», se quejaba de los mismos abusos de los que habla nuestro Montejano ${ }^{21}$.

\footnotetext{
13 J. Meseguer Fernández, «Relaciones del Cardenal Cisneros con su Cabildo catedral», Toledo Renacentista, Toledo, Centro Universitario, 1980, I (págs. 25-148), pág. 40.

${ }^{14}$ Marcel Bataillon, Erasmo y España, tr. Antonio Alatorre, México, Fondo de Cultura Económica, 1966, pág. 2.

15 Jodi Bilinkoff, The Avila of Saint Teresa: Religious Reform in a Sixteenth-Century City, Ithaca, Cornell University Press, 1989, pág. 32.

${ }^{16}$ Sebastián de Horozco, Cancionero, Bern, Herbert Lang, 1975. Francisco Márquez Villanueva, Espiritualidad y literatura en el Siglo XVI, Madrid, Alfaguara, 1968, pág. 113, nota 98.

${ }^{17}$ Canons and Decrees of the Council of Trent, tr. Henry Joseph Schroder, St. Louis, B. Herder Book Co., 1941, pág. 60.

${ }^{18}$ Ramón López-Arévalo, Juan, Un cabildo catedral de la Vieja Castilla: Ávila, su estructura jurídica, siglos XII-XX, Madrid, C.S.I.C., 1966, pág. 11.

${ }_{19}$ Ruth Pike, Aristocrats and Traders: Sevillian Society in the Sixteenth Century, Ithaca, Cornell University Press, 1972, págs. 55-56.

${ }^{20}$ Sara Tighman Nalle, God in La Mancha: Religious Reform and the People of Cuenca, 1500-1650, Baltimore, Johns Hopkins University Press, 1922, págs. 75-77.

${ }^{21}$ José Sánchez Amaro, Sermones predicables del loco don Amaro, ed. Luis Estepa, Madrid, Mayo de Oro, 1987, págs. 186-188.
} 
Para nuestro cuento basta decir que el canónigo A consiguió, es decir, «regresó», una canongía para el hijo del canónigo B y viceversa. El proceso «incestuoso» en que un canónigo ayuda a su propio hijo ayudando al hijo del otro es además un excelente ejemplo de la ayuda mutua, pero carece de ética y de moral.

Volvamos al manicomio toledano el día de la visita que hacían los canónigos A y B. Al entrar en dicha institución, empezaban a estudiar a quiénes echaban y a quiénes no. Empezaron por hablar con un paciente, un tal Montejano que, aunque loco, «hazía muchas cosas de hombre querdo y sabio. Y como allí le vieron los canónigos dixeron que para qué estaba allí aquel que no era loqo y comía el pan que otro verdadero loqo avía de comer». Les parecía que Montejano, ya cuerdo, tenía que marcharse.

Es obvio que Montejano quería permanecer en una casa que para él y para otros era no sólo su hogar predilecto, sino quizás el único. La calle sin comida y sin acogida no le atraían en mánera alguna, pero, ¿cómo podía Montejano combatir a esos canónigos todopoderosos y a lo mejor de casa señorial?, pues muchos canónigos venían del «estrato más elevado de la Iglesia española» según Domínguez Ortiz ${ }^{22}$. Montejano tenía que hacerles una burla para poder sobrevivir, una como, por ejemplo, la que les hizo Lázaro a su amo ciego y al cura de Maqueda.

Montejano les quería mostrar que él tenía tanto derecho a estar en el manicomio como ellos en la Sala Capitular catedralicia toledana. No hay que decir que tanto Montejano como todos los demás presentes sabían del ardid y picardía de estos dos canónigos para ayudar al hijo del otro. Para defenderse Montejano les pide permiso para contarles un cuento. Le dijeron que sí.

El cuento de Montejano es el siguiente: un ganadero invitó a dos pastores mayorales suyos a un banquete rústico para comer un caldero de migas, manjar fuerte compuesto de pan, aceite y ajos, pimientos, manteca, torreznos, miel y huevos, entre otros ingredientes (D de A II:566); una comida tan fuerte que puede satisfacer el hambre de cualquier persona.

Lo que ocurre es que el ganadero, el amo, quiere engañar a sus dos mayorales y burlarse de ellos poniéndoles obstáculos. Y por eso les:

[...] ata a cada uno de los pastores mayorales un cucharón en el braço derecho y de tal manera atado que ninguno de ellos podía doblar el braço ni llevar el cucharón a la boca por estar el braço atado y tiesto y díxoles, «Comed agora con esos cucharones las migas». Ellos bien henchían de migas las cuchares en la caldera. Mas en ninguna manera podían lle-

${ }^{22}$ Antonio Rodríguez Ortiz, Las clases privilegiadas en la España del Antiguo Régimen, Madrid, Ediciones Istmo, 1973, pág. 214. 
vallas a la boca. Entonçes quando el señor pensó que ellos no podrían comer las migas ellos se conçertaron de esta manera diziendo «dame tú a comer con tu cucharón. Y yo te daré a ti a comer con el mío». Y así se comieron las migas. Así avéis hecho vosotros dando el uno la calongía al hijo del otro y el otro al hijo del otro.

Como el lector verá, la reacción de los dos canónigos fue la de protegerse, porque bien entendían las verdades que pronunciaba Montejano. Por eso dijeron: "Echad de a'y a ese loqo», pero Montejano, el cuerdo loco, se supo defender diciendo: «Pues si soy loqo, bien puedo comer el pan de los loqos. Y así se quedó allí y estuvo hasta que murió». Creo que esta escena teatral pasó en el patio y en presencia de todos los habitantes de dicha institución y que ellos se reirían de los burlados canónigos. La respuesta astuta de Montejano venció a los amos picarescamente ${ }^{23}$.

Efectivamente el cuento de los dos comensales también tiene un carácter picaresco, porque los dos criados/mayorales vencieron a su amo por su astucia, sin fuerza física, sólo cerebral. Mi modo de interpretar estas dos partes que componen el cuento \# 238 es que recuerdan, como ya he dicho, los métodos de los que se valió Lázaro de Tormes para vencer a su amo ciego y al cura de Maqueda. Si es así, y creo que es así, entonces en este cuento \# 238 tenemos un cuento a lo picaresco o por lo menos a lo Lazarillo de Tormes.

En el caso del amo ciego, Lázaro llega a comer el pan, torreznos, longaniza, vino y uvas por medio de la astucia ${ }^{24}$. Y aunque el ciego le castiga, Lázaro al final se venga de él con el ardid del poste. Así, a su manera, también lo hacen los dos comensales del mal trato que les da su amo, pero la venganza de los comensales no es el castigo físico de su amo; su venganza es lograr comer lo que el amo quería impedirles, pues, en realidad, sólo tenían hambre.

En el caso del cura de Maqueda, éste coloca comida - muy poca - al alcance de Lázaro: las cebollas, tocino, carne, los panes del arca (Lazarillo Rico 47-50). Si el cura de Maqueda no le permitía a Lázaro comer poniendo un obstáculo tras otro en el camino, Lázaro a su manera momentáneamente vence a su segundo amo ${ }^{25}$. Sin duda alguna los dos comensales, como dos pícaros, sobreviven por su astucia ${ }^{26}$; como el pícaro, los dos co-

\footnotetext{
${ }^{23}$ LPG en general tiene bastantes cuentos acerca de la victoria de la astucia sobre la fuerza. Por ejemplo 14, 244, 148, 241, 341, 163, 234, 231, 232, 312, 332 entre otros.

${ }^{24}$ Lazarillo de Tormes, ed. Francisco Rico, quinta edición, Madrid, Ediciones Cátedra, 1990, pág. 27.

${ }_{25}$ Richard Bjornson, The Picaresque Hero in European Fiction, Madison, The University of Wisconsin Press, 1977, pág. 32.

${ }^{26}$ Peter N. Dunn, The Spanish Picaresque Novel, Boston, Twayne Publishers, 1979, pág. 12.
} 
mensales tienen que defenderse para sobrevivir, tienen que valerse por sí mismos o están perdidos ${ }^{27}$.

Es difícil establecer datos que unan este cuento genial de Horozco con alguna realidad ocurrida en Toledo o con personas específicas, pero tiendo a creer que este cuento es por lo menos un reflejo de la realidad toledana y de las frustraciones personales de Horozco. Desde luego la crítica anticlerical existía en Toledo en general y en particular contra los nombramientos fraudulentos a las canongías catedralicias. Las relaciones entre la Casa del Nuncio y el Cabildo se entrevén en nuestro cuento. $Y$ el tema de la ayuda mutua y la victoria de los de abajo es literario y aquí, en particular, picaresco.

Sólo un estudio de la historia de la Casa del Nuncio frente al Cabildo podría arrojar luz sobre quiénes eran los personajes toledanos del cuento de Horozco ${ }^{28}$. Sabemos, por ejemplo, que en 1561 el rector de la Casa del Nuncio era el sacerdote Funes ${ }^{29}$. No sabemos si aún lo era hacia 1570 , ni si Horozco alude o no al rector Funes. No figura el nombre de Montejano entre los habitantes de Toledo del año 1561. Del año 1558, momento de grandes hambres y de enfermedades, existían listas de los pobres, pero desafortunadamente han desaparecido.

No sabemos si el incidente es pura invención de Horozco o si efectivamente todo ocurrió como lo describe tan magistralmente. Creo que combi- na su fantasía con un incidente o anécdota sobre algo que bien podría haber ocurrido más o menos como lo describe nuestro autor.

La redacción de este cuento en su forma definitiva es de entre 1570 y 1572. Y si Montejano murió cerca de estos años, el incidente - si hubiera ocurrido- habría ocurrido bastantes años antes de 1570-1572 (LPG I:9-10), pues dice Horozco sobre los personajes: "Y hallaron en el dicho hospital por loqo a uno que se llamaba Montejano que estuvo en el dicho hospital algunos años...». Al final del cuento Horozco nos dice: «Y así se quedó allí y estuvo hasta que murió».

No puedo especular cuándo se hospedó este Montejano en el Hospital del Nuncio. Pero en LPG Horozco nos habla de incidentes que ocurrieron en sus años de adolescente como, por ejemplo, sus días estudiantiles en Salamanca entre 1526 y 1534 (LPG I:6). El cuento \# 107 corresponde históricamente a

\footnotetext{
${ }^{27}$ Robert Alter, Rogue's Progress, Harvard, Harvard University Press, 1965, pág. 3.

${ }^{28}$ Sólo se podría resolver este enigma con el escrutinio de los más de ochenta «Libros de cuentas» de la Casa del Nuncio que se custodian en el Archivo de Obra y Fábrica de la $\mathrm{Ca}$ tedral de Toledo. Ver Carmen Menéndez Torroja, Catálogo del Archivo de obra y fábrica de la Catedral de Toledo, Toledo, Diputación Provincial, 1977, págs. 188-210.

${ }^{29}$ Linda Martz y Julio Porres Martín-Cleto, Toledo y los toledanos en 1561, Toledo, I.P.I.E.T., 1974, pág. 89.
} 
1534 (I:152) y el \# 305 (II:373) a 1531. Sólo, como he dicho, con documentos de la época podríamos establecer la historicidad de nuestro cuento, sin ellos sólo podemos especular.

Lo que sí sé casi a ciencia cierta es que el tema del cuento de los dos comensales rústicos no es de la pluma de Horozco. Es un cuento tradicional posiblemente de varios orígenes: cristiano, chino, hindú, japonés y judío. Este cuento corresponde más o menos a la clasificación de Stith Thompson J1516.2 «Inhospitable host punished for hospitality» ${ }^{30}$, pero antes de comentar las fuentes de este cuento de Horozco más detalladamente, quisiera presentar algunos cuentos afines.

Empecemos con el mundo clásico. Uno de estos cuentos afines es una fábula de Esopo titulada La raposa y la cigüeña. En ella la raposa convida a la cigüeña, pero coloca la comida en un plato llano. De esta manera, la cigüeña con su pico tan largo no puede comerla. A su vez la cigüeña convida a la raposa, pero coloca la comida «en una vasija de vidrio en la qual no podía caber el rrostro et boca de la rraposa» ${ }^{31}$. De esta manera un comensal se vengó del otro. Pero en contraste con el cuento de Horozco los dos no se alimentaban mutuamente. Lo que el cuento de Horozco tiene en común con la fábula de Esopo es que la cigüeña invitadora se vengó de la raposa burladora ${ }^{32}$.

Otro cuento de la ayuda casi mutua es el del cojo vidente, del ciego fuerte y de la higuera del rey. Es un cuento talmúdico de gran dispersión. En él el ciego y el cojo son los guardas del huerto del rey, en el cual hay una hermosa higuera con suculentos higos que el cojo puede ver pero no puede alcanzar. Éste persuade al ciego fuerte a que le suba sobre los hombros y que el cojo le dirigirá a donde está la fruta. Así lo hacen, pero quien en este caso come los higos es el cojo y no el ciego. En este cuento hay ayuda pero el beneficio no es mutuo, pues sólo uno de los dos protagonistas come, el cojo ${ }^{33}$.

En contraste, en otra versión talmúdica, la de Midrash Rabbah, los dos se dan de comer y se satisface el hambre de los dos protagonistas ${ }^{34}$. Este cuento

\footnotetext{
${ }^{30}$ Stith Thompson, Motif-Index of Folk-Literature, Bloomington, Indiana University Press, 1957, IV; pág. 127 y Haim Schwarzbaum, Studies in Jewish and World Folklore, Berlin, Walter de Gruyter \& Co., 1968, pág. 178.

${ }^{31}$ Esopete ystoriado (Toulouse, 1488), ed. Victoria A. Burrus and Harriet Goldberg, Madison, Hispanic Seminary of Medieval Studies, 1990, pág. 52.

32 Aesop's Fables, tr. George Fyler Townsend, intro. Isaac Bashevis Singer, Garden City, Doubleday \& Company, s.a., pág. 173. Véase Schwarzbaum, pág. 179. Esta fábula también existe en la tradición oral popular española. Joaquín Díaz y Maxime Chevalier, Cuentos castellanos de tradición oral, Valladolid, Ámbito Ediciones, 1983, págs. 27-28.

${ }^{33}$ Sanhedrin, Hebrew-English Edition of the Babylonian Talmud, ed. Rabbi I. Epstein, London, The Soncino Press, 1969, pág. 919.

${ }^{34}$ Midrash rabbah (Leviticus), ed. H. Freedman, London, Soncino Press, 1961, IV:5, pág. 53.
} 
se encuentra en varias fuentes postbíblicas hebreas y en la obra de Epiphanius (c. 315-402) ${ }^{35}$.

La fuente del cuento del loco en Horozco, como hemos dicho, es de origen no establecido ${ }^{36}$. Sin embargo, un cuento contado por un santo hindú actual es de gran interés para nosotros. Se llama Heaven and Hell. En este cuento, en el infierno las almas se mueren de hambre porque cada una tiene atado a la mano un palito de casi tres metros de largo. Pero en contraste, en el cielo las almas sobreviven porque se alimentan las unas a las otras. La diferencia entre los dos grupos de comensales es que en el infierno se mueren de hambre a lo Tántalo y en el cielo comen armoniosamente ${ }^{37}$. De nuevo tenemos un excelente ejemplo de lo que es la ayuda mutua para sobrevivir.

El texto hindú no se refiere a ningún opresor específico, pero se ha de entender que quien oprime a estas almas en el infierno es el diablo ${ }^{38}$. Y así, las almas sobreviviendo, derrotan a su opresor (Narayan 192-194).

Según Haim Schwarzbaum, este cuento con sus variantes judías es sumamente común (Schwarzbaum 178-179). He tratado de encontrar, sin éxito, una versión española del cuento de la alimentación mutua. No creo que figure en la tradición española escrita, pues he examinado las fuentes tradicionales en la literatura peninsular. Y hasta he consultado a varios especialistas, otra vez sin éxito, sin encontrar nada en absoluto en España.

Otro ejemplo de este cuento de Horozco que he encontrado en lengua española es de narradores sefardíes oriundos de Turquía. Primero lo encontré en el libro de Reginetta Habouch bajo la categoría AT 981, Wisdom of Hidden Old Man saves Kingdom, en el que cuatro herma-

\footnotetext{
${ }^{35}$ Enclyclopedia Judayca, Jerusalem, The MacMillan Company, 1972, VI:1099.

${ }^{36}$ Kirin Narayan, Storytellers, Saints, and Scoundrels: Folk Narrative in Hindu Religious Teaching, Philadelphia, University of Pennsylvania Press, 1989, pág. 200.

${ }^{37}$ «Hell is like a great banquet at which everyone is given four-foot long chopsticks so nobody can feed himself; heaven is like a banquet at which everyone is given four foot-long chopsticks and everybody feeds each other». Terrence W. Tilley, Story Theology, Michael Glazier, Wilmington, Delaware, 1985, pág. 88. Pero Tilley no sabe el origen de este cuento (Tilley 89, nota 8). Una variante de este mismo cuento también se encuentra en el Midrash. William B. Silverman, The Sages Speak: Rabbinic Wisdom and Jewish Values, Northvale, Nero Jensen, Jason Aronson, Inc., 1989, pág. 199.

${ }^{38}$ En español existe el proverbio «Quien con el diablo haya de comer, larga cuchara ha menester». Luis Martínez Kleiser, Refranero general ideológico español, Madrid, Real Academia Española, 1953, pág. 194, \# 17.643. El mismo proverbio también existe en inglés y aparece en Chaucer, John Haywood (1540) y Shakespeare. John Bartlett, Familiar Quotation, fourteenth edition, Toronto, Little, 1968, págs. 1686-1690. Puede ser que este proverbio comparta raíces con el cuento de Horozco. Pero según lo que he visto, parece que tiene otro sentido distinto al del cuento de nuestro escritor toledano. En el caso de Horozco la boca no está demasiado lejos de la comida. En los otros casos la comida está demasiado lejos de las personas.
} 
nos están sentados dos a dos unos frente a otros ${ }^{39}$. Y por consejo de su anciano padre se sentaron así. De esta manera pudieron tanto alimentarse como burlarse del rey que les había atado las manos a todos los comensales con grandes cucharones.

Este cuento combina otro cuento que también Horozco incluye en su libro, los números 148, 241, En los antiguos está la sabiduría, cuya fuente parece ser La crónica troyana. Pero en las ediciones de esta crónica que he podido ver no he encontrado este cuento de Horozco. Este aspecto del padre/viejo sabio tiene bastantes precedentes tanto en la Península Ibérica como en otros lugares (Haboucha 497)» ${ }^{40}$.

Nuestra versión sefardí que combina los dos cuentos de Horozco se 1lama El rey i el padre viejo. Lo publicó Matilda Koen-Sarano, la folklorista israelí, en $1986^{41}$, pero ella lo había oído antes, en los años cincuenta ${ }^{42}$. El cuento de los comensales pronunciado por el loco de la Casa del Nuncio no se ha hallado en fuente escrita peninsular ninguna, pero sí existía porque, si no fuera así, no habría aparecido en el cuento \# 238 de Horozco. De algún lugar o por alguna vía habría llegado a España. Pero hay que preguntarse, ¿cómo forma parte del patrimonio intelectual y artístico de nuestro autor? ¿Cómo se transmitió de la parte oriental del Mediterráneo, del saliente al poniente? O quizás fue viceversa, es decir, de España al Imperio turco. Puesto que no hay fuente conocida escrita española hay que concluir que el cuento sobre los dos comensales tiene que haber existido sólo oralmente.

\footnotetext{
${ }^{39}$ Reginetta Haboucha, Types and Motifs of the Judeo-Spanish Folktales, New York, Garland Publishings Inc., 1982, pág. 495. Un segundo ejemplo forma parte de la tradición oral andaluza (Aldeaquemada, Jaén), Textos andaluces en transcripción fonética, ed. Manuel Alvar y Pilar García Mouton, Madrid, Editorial Gredos, 1995, págs. 262-263. Agradezco a Pilar García Mouton el haberme mostrado este cuento.

${ }^{40} \mathrm{Y}$ sobre el loco que al principio un rey creía curado y que al final le dio una bofetada por sus sandeces también existe en la tradición sefardí de los Balcanes. Cynthia M. Crews, «Textos judeo-españoles de Salónica y Sarajevo con comentarios lingüísticos y glosario», Estudios sefardies, Anejo de Sefarad, II, 1979 (págs. 91-258), págs. 123-124.

${ }^{41}$ Matilda Koen-Sarano, Kuentos del folklor de la famiya djudeo-espanyola, Yerushaláyim, Kaza Editora Kana, 1986, págs. 43-45.

42 Carta de Matilda Koen-Sarano (Yerushalyim, 16-3-1994). «Muy estimado Profesor Weiner, resiví Su letra del 24/2/94 kon la fotokopia del kuento inkluído i La rengrasio muncho.

La únika koza ke Le puedo dizir sovre el kuento ke se topa en mi livro es ke yo lo oyí oralmente en dos períodos diversos. Lo uzava kontar mi nona, Vida Hadjés de Izmir en los anyos ' 50 , i mi padre, Alfredo Sarano, ke nasió en Aydín (Turkía), i bivió en Rodes, en Milano i en Bené Berak (Israel), asta el 1990, anyo de su muerte.

Peró puedo adjustar ke el motivo del ayudo de las kucharas se topa i en un kuento ashkenazí sovre el Inferno i el Paradizo, ke yo oyí kontar oralmente. Esto es todo lo ke sé yo sovre este sujeto, ma me imajino fasilmente ke es muy antiko.

Resiva mis mas kordiales saludos.»
} 
Propongo que el cuento de los comensales era parte de la tradición oral judeo-española, una tradición que Horozco conocía mejor que nadie. A lo mejor Horozco se lo oyó contar a miembros de la comunidad conversa toledana de la cual — quisiera o no- formaba parte. Quizás lo oyó contar estando aún en el regazo de su propia madre, María de Soto, de ascendencia inmediata judía.

Ahora llegamos al tema del loco en la creación literaria de Horozco. El loco o el bufón tiene una historia cuyas huellas podemos seguir hasta la Antigüedad, época en que se nombra al bufón y al loco. Divertían a los reyes según la historia, y a los dioses según la mitología ${ }^{43}$. Los reyes los querían porque los locos ayudaban a «matar el tiempo..., dicen las verdades y son cándidos» (Doran 17). Esta candidez expresada ante el rey por cualquier otro sería razón para decapitarlo ${ }^{44}$.

En Castilla, por ejemplo, en la corte de Alfonso el Sabio existían bufones y locos como figuras literarias y él los presentaba. Desde el siglo XIV en España empieza a florecer la literatura bufonesca. Según Márquez Villanueva, el bufón y el loco fingido o natural reemplazan al juglar a lo largo del siglo XV y en el siglo XVI. Dos bufones de ese siglo que destacan son Francisco de Zúñiga y el médico Francisco de Villalobos ${ }^{45}$.

Aunque el bufón podía criticar con impunidad hasta al rey, ésta, sin embargo, no le salvó la vida a Zúñiga, quien murió apuñalado por un enemigo personal ${ }^{46}$. Quizás por esa razón Horozco decidió no publicar sus obras, en particular su LPG y su Cancionero. El bufón o loco podía criticar, pero a la vez conocía las reglas del juego (Márquez Villanueva Sebastián de Horozco y la literatura 396); si sobrepasaba los límites, la Inquisición también podía perseguirle por sus chocarrerías escandalosas (Gilman 97, Márquez Villanueva Sebastián de Horozco y la literatura 395).

Según se ha visto, la mayoría de los bufones y locos, ya desde $E l$ cancionero de Baena hasta la época de Horozco, eran conversos ${ }^{47}$. Estos bufones se sentían oprimidos por los estatutos de limpieza de sangre que les excluían a ellos, y a los conversos en general de una existencia justa. Deseaban con gran fervor expresar su angustia y deseos, según Stephen Gil-

\footnotetext{
43 John Doran, The History of Court Fools, New York, Haskell House, 1966, pág. 3.

${ }^{44}$ Desiderio Erasmus, The Praise of Folly, ed. y tr. Leonard F. Dean, New York, Hendricks House, 1969, pág. 75.

${ }^{45}$ Francisco Márquez Villanueva, «Sebastián de Horozco y la literatura bufonesca», Homenaje al profesor Antonio Vilanova, Barcelona, Universidad de Barcelona, 1989 (págs. 393431), págs. 393-395.

46 Stephen Gilman, «A Generation of Conversos», Romance Philology, XXXIII, 1979 (págs. 87-101), pág. 97.

47 Francisco Márquez Villanueva, «Jewish "Fools" of the Spanish Fifteenth Century», Hispanic Review, L, 1982 (págs. 385-409), pág. 408.
} 
man, «The problem was simply how to utilize historical pessimism creatively» (Gilman 100). Los gritos y chocarrerías de estos bufones y locos, según Márquez Villanueva, se hicieron «the only avenue for the affirmation of human dignity and intellectual freedom. For the conversos tearing down literary barriers became tantamount to neutralizing the social constraints under which they were suffocating» (Márquez Villanueva Jewish 408).

En la creación literaria del converso Sebastián de Horozco tenemos ejemplos de obras bufonescas. Lo cierto es que la obra de Horozco «es una importante adición a la literatura bufonesca» (Márquez Sebastián de Horozco y la 396), por eso no nos ha de sorprender que su Cancionero contenga excelentes ejemplos de un loco o quizás más bien de un loco fingido, pero la diferencia entre Horozco y, por ejemplo, Villalobos es que éste se ríe de ello y no se muestra demasiado amargado. Horozco, al contrario, odia a los conversos y, a causa de sus propias raíces, se odia a sí mismo (Weiner Padres, passim).

En este cuento de la Casa del Nuncio, Horozco se quejaba veladamente de las muchas oportunidades que se les escapaban a sus propios hijos, los sacerdotes Juan y Sebastián, para subir la escalera socio-económico-profesional. Es decir, Horozco veía en su entorno a personas que alcanzaban los mayores niveles en la jerarquía eclesiástica española, pero sus hijos no los alcanzaban. Horozco comparaba siempre las vidas de sus hijos con las de Diego y Antonio de Covarrubias, eclesiásticos de altísima categoría que sí alcanzaron obispados y canonicatos ${ }^{48}$. Para los hijos conversos de Horozco esto no fue posible en lugares que exigiesen estrictamente la limpieza de sangre. En el loco Montejano vemos una manifestación de la ira y agonía de Horozco, y de muchos otros conversos, cuya sangre semita - por leve que fuera- les impedía obtener los derechos que como cristianos merecían (Márquez Villanueva Jewish 408).

Por medio de este «loco», Horozco expresa su oposición a cómo los canónigos en Toledo nombraban a los aspirantes al Cabildo Catedralicio toledano. No podía contener su enojo de que dos sacerdotes — canónigosnombrasen a sus propios hijos, hijos, a lo mejor, ilegítimos. Si eran buenos canónigos estos dos vástagos, no lo sé, pero el caso es que nadie -inclusive los hermanos Covarrubias - pudo ayudar a los dos hermanos Horozco para conseguir una canongía en la catedral toledana o en cualquier otro lugar donde exigieran limpieza de sangre.

\footnotetext{
48 Habría que aclarar que Diego de Covarrubias habiendo sido obispo en Ciudad Real, Segovia, Cuenca - no llegó a ocupar esta silla episcopal - hizo todo lo posible para ayudar a los hijos de Horozco allí y en cualquier parte que pudiera (Weiner Padres 120). En este caso de verdadero nepotismo nuestro Horozco no se queja.
} 
El juglar medieval se convierte en bufón o loco natural o fingido. $\mathrm{Y}$ estos dos últimos se convierten con el correr de los años en el pícaro. Con razón dice Márquez Villanueva: «El recorrido de la materia bufonesca conduce por sí mismo, la mirada hacia un remate inevitable en el Lazarillo de Tormes» (Márquez Villanueva, Sebastián de Horozco y la literatura 426). Efectivamente Horozco dice en este cuento que tanto los locos como los niños dicen la verdad. Y Lázaro de Tormes como niño y aun como adulto también la dice.

Esto nos lleva a preguntarnos: ¿tiene este cuento o cuentecillo rasgos de la novela picaresca? Habría que concluir que sí.

Quiero definir este cuento de Horozco y colocarlo dentro de su tradición correspondiente. Para empezar, cabe dentro de las descripciones que da Maxime Chevalier al cuentecillo y al cuento, que «es un relato breve, de tono familiar, en general de forma dialogada, que suele concluir con una réplica aguda... que produce, o intenta producir efecto jocoso» ${ }^{49}$.

Muchos de estos cuentecillos se incorporaban o emanaban de colecciones impresas en el Siglo de Oro. A la vez muchas colecciones no llegaron a imprimirse ${ }^{50}$. Al contrario muchas han desaparecido y desde hace siglos quedan enterradas en el olvido total (Chevalier Folklore 17). En el caso de LPG de Horozco sus cuentos se extraviaron, pero afortunadamente ya han visto la luz.

Algunas de las recopilaciones impresas de cuentecillos más conocidas en la época de Horozco son El sobremesa... (1569) de Juan de Timoneda y La floresta... (1574) de Melchor de Santa Cruz (Chevalier Cuentecillos 17). A veces el cuentecillo se va novelizando (Chevalier Cuentecillos 31), es decir, que va incorporándose a obras más extensas. Excelente caso es el mismo Lazarillo de Tormes ${ }^{51}$. Sin duda alguna estos rasgos sobre el cuentecillo y sobre el cuento en general que presenta Maxime Chevalier caben perfectamente dentro de lo que Horozco aquí presenta al lector en el cuento \# 238.

Según Axel Olrik la narrativa como el cuento \# 238 de Horozco «designates a report of an event that is passed along by word of mouth without the informants' being able to check its origenes or its previous authorities» ${ }^{52}$. Aquí también se puede decir que este cuento de Horozco corres-

\footnotetext{
49 Maxime Chevalier, Cuentecillos tradicionales de la España del Siglo de Oro, Madrid, Editorial Gredos, 1975, pág. 9, y Maxime Chevalier, Cuentos españoles de los siglos XVI y XVII, Madrid, Taurus, 1982, pág. 10.

${ }^{50}$ Maxime Chevalier, Folklore y literatura: el cuento oral en el Siglo de Oro, Barcelona, Editorial Crítica, 1978, pág. 64.

${ }^{51}$ María Rosa Lida de Malkiel, «Función del cuento popular en el Lazarillo de Tormes», Actas del primer congreso internacional de hispanistas, Oxford, The Dolphin Book Co., 1964 (págs. 349-359), págs. 349, 358.

52 Axel Olrik, Principles for Oral Narrative Research, tr. Kirsten Wolf and Jody Jensen, Indiana University Press, Bloomington, 1992, pág. 1.
} 
ponde a la narrativa que podría ser de tradición oral por no existir - que nosotros sepamos - antecedente conocido escrito. Los rasgos del cuento folklórico, según Stith Thompson, incluyen «all forms of prose narrative, written or oral, which have come to be handed down through the centuries» ${ }^{53}$. Una vez establecido el cuento \# 238 como narración de tipo folklórico podemos sugerir que también tiene rasgos de carácter picaresco.

En la narrativa picaresca tenemos un antihéroe que lucha contra el de arriba, su señor y amo. El criado pícaro tiene que valerse de su astucia para poder sobrevivir y en la narración de su vida el pícaro hace crítica social ${ }^{54}$. Su astucia en particular le defendía contra los clérigos poderosos (Chandler 23). Y en gran parte la protesta principal de Lázaro es contra la hipocresía religiosa. Tal protesta anticlerical la coloca sin la menor duda dentro de las tendencias reformadoras del malvivir del clero ${ }^{55}$.

Efectivamente el cuento \# 238 de Horozco tiene las siguientes características de la novela picaresca. El loco (¿fingido?) Montejano gana su pan como Lázaro por su astucia y logra enseñar a los dos clérigos valiéndose de un tipo de guerra psicológica a la manera en que Lázaro come las uvas del ciego. A causa del mal trato y de la humillación pública que había recibido a manos de su primer amo, Lázaro se venga ${ }^{56}$. Así se venga Montejano de los dos canónigos. Sin la menor duda este cuento de Horozco es de carácter picaresco.

Sobre el anónimo autor del Lazarillo de Tormes se ha escrito mucho. Los nombres de los candidatos principales - en orden alfabético- son Sebastián de Horozco, Diego Hurtado de Mendoza, Hernán Núñez de Toledo, Pedro de Rúa, los hermanos Valdés y el jerónimo Juan de Ortega (Lazarillo Rico 31-44). Hasta hace poco no se había podido estudiar debidamente a Sebastián de Horozco como autor del Lazarillo de Tormes. Es así porque hasta este momento no habíamos tenido ejemplos de la prosa narrativa de Horozco. Los que se inclinaban hacia la paternidad literaria de Horozco se basaban principalmente en la coincidencia temática y temperamento de los dos autores ${ }^{57}$.

Márquez Villanueva nos comunica: «Los puntos de contacto son demasiado numerosos y demasiado importantes para ser fruto de una mera coin-

\footnotetext{
53 Stith Thompson, The Folktale, Berkeley, University of California Press, 1977, pág. 4.

${ }^{54}$ Frank Wadleigh Chandler, Romance of Roguery: An Episode in the History of the Novel, New York, Burt Franklin, 1961, pág. 16.

${ }_{55}$ Alexander A. Parker, Literature and the Delinquent: The Picaresque Novel in Spain and Europe, Edinburgh, The University Press, 1967, pág. 29.

${ }^{56}$ Alexander Blackburn, The Myth of the Picaro and the Transformation of the Picaresque Novel, Chapel Hill, The University of North Carolina Press, 1979, pág. 39.

${ }^{57}$ Francisco Márquez Villanueva, «Sebastián de Horozco y El Lazarillo de Tormes», Revista de Filología Española, XLI, 1957 (págs. 253-339), pág. 307.
} 
cidencia ambiental. Apenas si hay en el Lazarillo un tema literario, un tópico, un pensamiento, un recurso expresivo que no pueda encontrarse en Horozco... Estimamos por ello que hasta el momento hemos de considerar a Horozco, por lo menos, como el más calificado aspirante a la paternidad del Lazarillo» (Márquez Villanueva Sebastián de Horozco y el Lazarillo de Tormes 338-339).

En contraste con la propuesta de Márquez Villanueva, Francisco Rico opina: «El fragmento de la Representación en que aparecen el ciego y su criado es una muestra sumamente adecuada de la paleta de Horozco: ni en las demás páginas del Cancionero, ni en el Libro de proverbios, ni en las relaciones toledanas, hay nada equiparable a la lengua del Lazarillo, y sí continua cortedad de expresión, grosería (vid. arriba n. ${ }^{\circ} 26$ ), falta de imaginación narrativa. Tal vez de ningún otro de los escritores propuesto para la autoría puede decirse con tanta seguridad como de Sebastián de Horozco que el estilo de toda su obra desmiente la hipótesis en términos perentorios» (Lazarillo Rico 43).

Ni quito ni pongo, pero creo que la hipótesis de Francisco Márquez Villanueva aún queda en pie. Y con el estudio del recién publicado LPG se podrá arrojar más luz sobre la paternidad literaria del misterioso Lazarillo de Tormes. 